\title{
PROPOSTA DE REESTRUTURAÇÃO PARA O PARQUE IPANEMA NO MUNICÍPIO DE IPATINGA-MG
}

\author{
Anna Luiza Lopes Pereira Martins - annaluizal_@hotmail.com \\ Pollylian Assis Madeira - pollylian.madeira@uemg.br \\ Marcos Antônio Pereira Coelho - marcos.coelho@uemg.br
}

\begin{abstract}
Resumo: Os parques urbanos foram criados após o período da Revolução Industrial para o desenvolvimento de atividades de lazer no tempo livre adquirido principalmente pelos trabalhadores. O presente trabalho tem como tema o Desenvolvimento Local, objetivando propor a reestruturação de alguns equipamentos para o Parque Ipanema, no município de Ipatinga-MG. Especificamente, pesquisou-se sobre o tema proposto para melhor embasamento; aplicação de questionários online e in loco, identificando as potencialidades e limitações do parque municipal, que contribuíram para as sugestões da reestruturação do Parque Ipanema. Justifica-se o presente trabalho após observar que o parque possui grande demanda de visitação com frequência, mas encontra-se com sua infraestrutura precária. Constatou-se após análise dos dados obtidos com os entrevistados que o Parque necessita de uma reestruturação em alguns equipamentos e principalmente na segurança.
\end{abstract}

Palavras-chave: Desenvolvimento Local; Parque Urbano; Reestruturação; Atrativo Turístico.

\section{INTRODUÇÃO}

O conceito de lazer é explicado por Dumazedier (1973, p.34) como um conjunto de atividades a qual a pessoa pode usufruir em seu tempo livre, seja para descansar, entreter-se ou exercer qualquer atividade que não seja de ocupação profissional, familiar e social. O Parque Ipanema do município de Ipatinga - MG é um exemplo desta conceituação, pois oferece área de lazer com pista para caminhada e corrida, lago com ilha, cata-ventos, brinquedos, anfiteatro e quadras poliesportivas, além da sua beleza natural que é composta por cerca de 12 mil árvores. Após várias visitas realizadas ao local, notou-se que ele possui um elevado índice de visitação com frequência, mas que em uma visão geral esse encontra-se com sua infraestrutura precária.

Este trabalho tem como tema, Desenvolvimento Local, buscando responder: "De que forma o Parque Ipanema, do município de Ipatinga-MG, pode proporcionar entretenimento, conforto e segurança para os turistas?". O objetivo geral da pesquisa é propor a reestruturação de alguns equipamentos para o Parque Ipanema, no município de Ipatinga-MG. Especificamente, pesquisou-se sobre o tema proposto para melhor embasamento; aplicação de questionários online e in loco, identificando as potencialidades e limitações do parque municipal, que contribuíram para as sugestões da reestruturação do Parque Ipanema.

Nas disciplinas de Desenvolvimento Local e Turismo e Marketing Turístico foram 
estudados os fatores importantes para o desenvolvimento de uma localidade, observando sua estruturação, sustentabilidade e como planejar ações responsáveis de modo a divulgar o que se oferece em um produto turístico. Com os estudos, sentiu-se a necessidade de uma reestruturação do Parque Ipanema, no município de Ipatinga-MG, observando suas potencialidades para o lazer dos turistas e moradores, propondo possíveis sugestões para melhoria no funcionamento deste local de modo a atrair mais visitantes e melhor estruturação do parque.

Metodologicamente, realizou-se pesquisas bibliográficas contando com alguns autores que tratam os assuntos sobre turismo, lazer e parque urbano, para fundamentação do trabalho. Aplicouse questionário online com os moradores e visitantes de Ipatinga-MG para a verificação dos dados a respeito do Parque Ipanema, como também aplicação in loco aos comerciantes que trabalham no parque e visitantes. Seria aplicado questionário com o Poder Público, porém, devido ao período eleitoral, o profissional do turismo atuante no município, decidiu responder apenas enquanto pessoa física. Para maior confirmação do que foi citado no trabalho, realizou-se uma visita técnica para registro de imagens do local.

Pode-se concluir que o Parque Ipanema necessita de uma reestruturação em todos os seus espaços, desde os equipamentos de segurança até a limpeza dos banheiros, com um controle no fluxo de usuários no espaço público para evitar que seja alvo de vandalismo.

\section{TURISMO, LAZER E PARQUES URBANOS}

No Brasil, o lazer se trata do tempo livre utilizado para exercer atividades que proporcionam prazer e descanso para o indivíduo, seja gratuito ou não. O tempo livre, que é usufruído atualmente, resulta do período pós-revolução industrial onde os trabalhadores se distraíam com atividades de lazer. O turismo e o lazer foram de extrema importância neste período, visto que os autores Aquino e Martins (2007, p.480) também destacam que: "No caos entre necessidades econômicas e existenciais, o homem contemporâneo se vê dividido entre as obrigações impostas por suas atividades laborais e o desejo de libertar-se dessas tarefas e, assim, poder usufruir um tempo para si”.

Coimbra (2008, p. 16) diz que para além do desenvolvimento pessoal, as atividades de lazer têm evidenciado potencialidades para o desenvolvimento dos espaços onde se integram, 
tornando-se um importante elemento de desenvolvimento local. Isso significa que o funcionário que usufrui o seu tempo de lazer, consegue produzir mais em uma empresa e contribuir para o seu crescimento, e foi no período pós revolução industrial que o trabalhador adquiriu o direito ao lazer para extravasar o seu cansaço. Foi assim que surgiram os primeiros Parques Urbanos, as primeiras paisagens naturais através da urbanização e a industrialização dos países que se deu primeiramente na Europa e nos Estados Unidos, para o desenvolvimento social e cultural do ser humano. Silva e Pasqualetto (2013, p. 287) citam:

os parques, definidos como equipamentos públicos, têm a sua história marcada através de experiências inglesas, francesas e norte-americanas; os primeiros parques urbanos surgiram paralelamente à formação das cidades em fins do século XVIII, sendo o seu apogeu nas décadas de 1850 e 1860, na Europa e nos Estados Unidos (SILVA; PASQUALETTO, 2013, p. 287).

Com o crescimento acelerado da urbanização, as cidades começaram a ficar "cinzas" e o verde se destacar apenas em quintais de casas e pequenos jardins. Não havia nenhuma preocupação com a natureza interagindo a população com a interação entre a natureza e a população. Como cita Macedo (1999, p. 26) nesse período "a vegetação está sempre ausente do espaço urbano central; chafarizes e cruzeiros são praticamente os únicos elementos que se destacam no espaço público”.

Decorrente a história dos parques, tais também possuem as classificações bem como características. E acabou tornando uma característica de interesse político, capaz de aumentar a qualidade de vida do cidadão com entretenimento social, cultural e ambiental. Segundo Macedo (1999, 2003, p. 293) existem três grandes linhas na arquitetura paisagística: a Linha Eclética (tratase da natureza adaptada pelo homem dentro de uma visão romântica), a Moderna (décadas de 1930 e 1940 em que a vegetação nativa era sobrevalorizada) e a Linha Contemporânea (características pós-moderna). O mesmo autor (MACEDO, 2003, p.294) também cita que, apenas a partir do século XX, os parques que antes tinham como objetivo a contemplação, incluem novas características de lazer como praça de alimentação, espaço para eventos e demais atividades, surgindo outras denominações como parques ecológicos. O Parque Ipanema, localizado no município de Ipatinga-MG, na região metropolitana do Vale do Aço é um exemplo que se enquadra na linha contemporânea devido as características citadas por Macedo (2003, p.294) e por 
sua estruturação apresentar-se como parque ecológico.

\subsection{Ipatinga e Parque Ipanema - O Vale além do aço}

De acordo com o site oficial da prefeitura de Ipatinga (2003) ${ }^{1}$, com a construção da Estrada de Ferro Vitória-Minas, que ligava Minas Gerais ao estado Espirito Santo, começaram a vir os primeiros habitantes. Em 1922 foi inaugurada a Estação de Pedra Mole, e atualmente se encontra tombada pelo patrimônio histórico e artístico-cultural. Em 1930, o trajeto foi mudado para onde se encontra o projeto da cidade atual (Estação Memória), a qual em 2018, foi tombada e desativada, sendo utilizada apenas como museu. Em 1953, surgiu o Município de Ipatinga, sendo distrito do município de Coronel Fabriciano e, em 1964 sua emancipação.

O desenvolvimento da cidade foi contribuído por duas empresas que se instalaram no local, sendo uma delas a Usiminas, gerando empregos e migrações. Por esse motivo, houve a necessidade de criar hospitais, escolas e demais infraestruturas básicas para os trabalhadores. Em 1961, foi inaugurado o Grande Hotel em Ipatinga, que se encontra tombado e desativado. A Usina Intendente Câmera - USIMINAS, foi inaugurada dia 26 de outubro de 1962, e oito anos depois a Usina Mecânica USIMEC. O município se destaca por ser uma metrópole e pelo turismo de negócios, visto que possui várias empresas grandes no local.

A apreciação da beleza das paisagens naturais tem apressado o crescimento de produção de panoramas urbanos e, sustentado uma formação permanente do significado do conceito de meio ambiente. Segundo Lima (2003, p.70), no ano de 1990 as paisagens naturais se destacaram em relação à preferência dos turistas, principalmente pela monotonia dos roteiros convencionais e estresse gerado nos grandes centros urbanos (PREFEITURA DE IPATINGA, 2003).

O Parque Ipanema era um sonho estudado desde 1970, quando a paisagem de Ipatinga, dominada pela usina siderúrgica, tinha ares cinzentos. Uma década depois, Roberto Burle Marx desenvolveu o projeto paisagístico que, para a época, foi considerado audacioso. Localizado entre os bairros Iguaçu, Jardim Panorama, Veneza, Centro e Novo Cruzeiro; com sua área estimada em $1,1 \mathrm{~km}^{2}$, dentro da qual foram plantadas cerca de 12 mil árvores, possui quadras poliesportivas, cata-vento, playground, anfiteatro, Parque da Ciência, praça de alimentação e demais equipamentos para os visitantes, sendo considerada uma das maiores áreas verdes do país dentro

\footnotetext{
${ }^{1}$ Prefeitura de Ipatinga. Disponível em: http://www.ipatinga.mg.gov.br/ Acesso em: 22 jul. 2018 
de um perímetro urbano (PREFEITURA DE IPATINGA, 2003).

\section{METODOLOGIA}

Para a fundamentação teórica do presente estudo, foi realizada inicialmente pesquisa bibliográfica com autores que abordam o tema proposto, sendo alguns deles Silvio Soares Macedo, Janaína Barbosa Silva, Antônio Pasqualetto e José Augusto de Morais (historiador do município de Ipatinga-MG, autor da coletânea "IPATINGA - Cidade Jardim").

Foi realizada no dia 24 de agosto de 2018 visitação técnica para analisar o local em estudo, registrando através de imagens os equipamentos e os espaços, como comprovação do estado atual do Parque Ipanema, possibilitando também identificar as potencialidades e limitações do parque municipal. Para maiores informações, foram realizadas também pesquisas qualitativas e quantitativas in loco e online. No mês de julho foi aplicado aos comerciantes, e no mês de agosto para o poder público e visitantes do Parque. Ao aplicar o questionário aos comerciantes, dos quais 49 barracas são devidamente registradas, apenas 14 destes quiseram responder o questionário. Os outros se negaram ou não se encontravam em funcionamento.

Ao procurar o poder público na prefeitura municipal, os setores se negaram a responder a entrevista alegando não serem responsáveis pelo parque. Após, foi direcionado para os setores: Sec. Municipal de Turismo, Sec. Municipal de Esporte e Lazer, Sec. Municipal de Serviços Urbanos e Meio Ambiente, e por último o DEMAM - Departamento de Meio Ambiente. Apenas uma pessoa, responsável pelo setor de Turismo no Município de Ipatinga-MG, respondeu à entrevista na condição da troca de "Poder Público" por "Turismóloga".

O questionário aplicado online foi estruturado com respostas de SIM ou NÃO, utilizando a escala de likert para as respostas em que se apresentam múltipla escolha (1 a 5), e, duas perguntas abertas para sugestão. O questionário aplicado in loco com os comerciantes foi estruturado, e a entrevista aplicada aos visitantes foi a mesma aplicada online. Após aplicado os questionários e entrevistas, realizou-se análise dos dados obtidos para a construção das sugestões de reestruturação para o Parque Ipanema.

\subsection{Visita Técnica}

No dia 24 de agosto de 2018 foi realizada visita técnica ao Parque Ipanema para verificação 


\section{mylhos}

Journal homepage

http://www.mythos.unis.edu.br

\section{ISSN 1994-0098}

da estruturação do espaço in loco e efetuar registro de imagens para comprovação e análise.

Observou-se grande potencialidade no local, mas registrou-se equipamentos e espaços frágeis, sem preservação e funcionalidade. Para maior comprovação de tal argumento, foram coletadas algumas imagens para melhor visualização, observando que alguns equipamentos não possuem os devidos cuidados.

Figura 1: Campo de Futebol

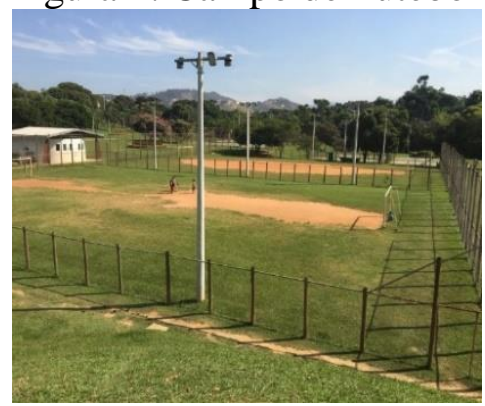

Fonte: Visita técnica (2018)

Figura 4: Lixo acumulado

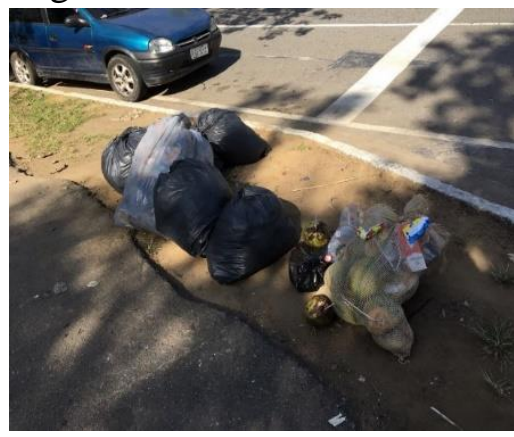

Fonte: Visita técnica (2018)

Figura 7: Banheiro

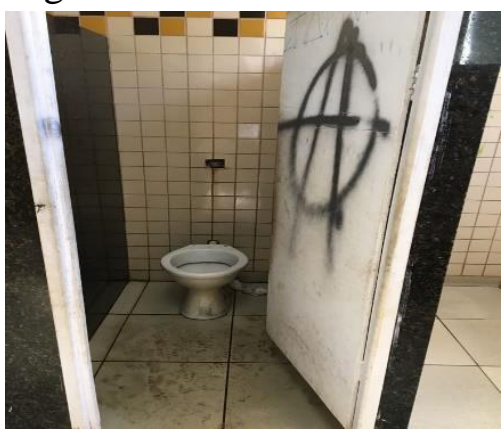

Fonte: Visita técnica (2018)
Figura 2: Placa de proibição

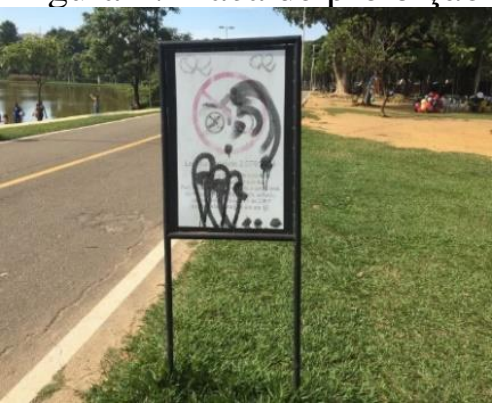

Fonte: Visita técnica (2018)

Figura 5: Barracas do Parque

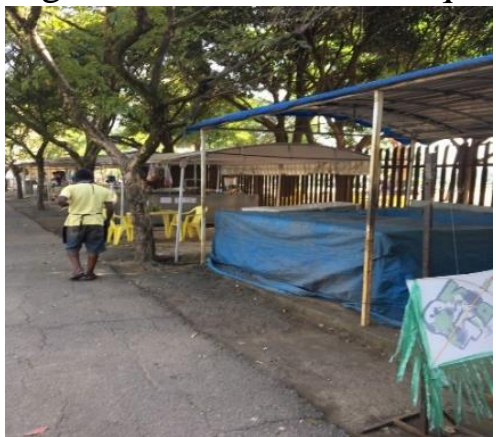

Fonte: Visita técnica (2018)

Figura 8: Para deficiente

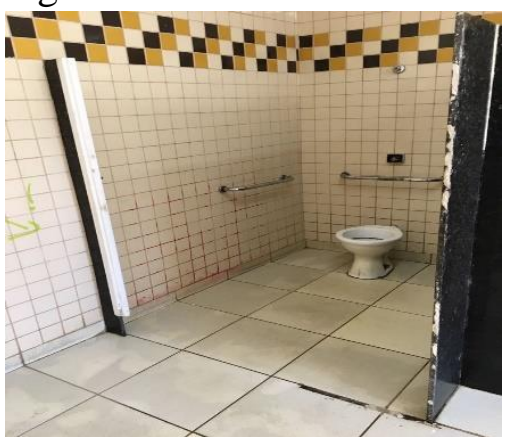

Fonte: Visita técnica (2018)
Figura 3: Placa de alerta

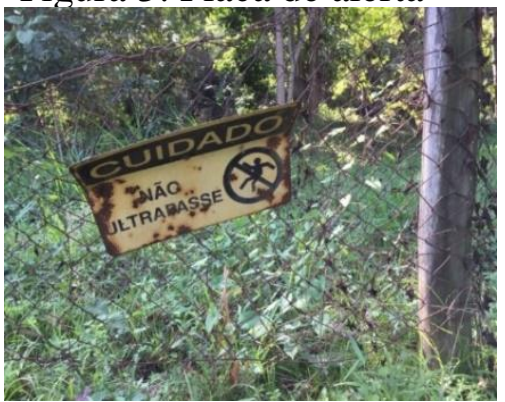

Fonte: Visita técnica (2018)

Figura 6: Banheiro do Parque

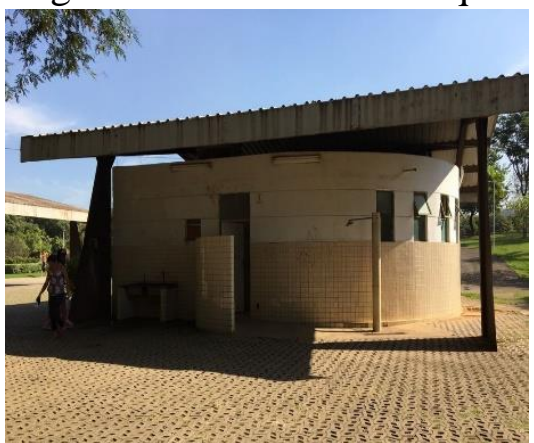

Fonte: Visita técnica (2018)

Figura 9: Pia do banheiro

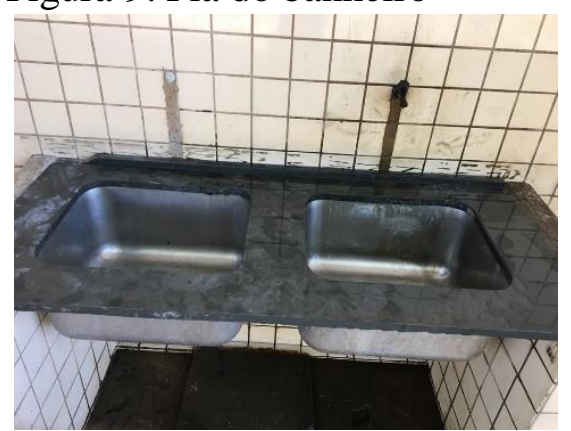

Fonte: Visita técnica (2018) 
Observou-se também que possuem poucas placas de sinalização turística e as que haviam estavam danificadas ou sem manutenção, assim como o campo de futebol com o gramado precário. O lixo acumulado e outros impactos negativos, contribuem com a poluição visual. Os banheiros com a estrutura danificada por ato de vandalismo, não possuem todas as portas, algumas de suas dependências se encontram sujas, sem papel higiênico e lixeira. Não possui fraldário e o banheiro de deficientes encontra-se sem porta. As pias para higienização das mãos não possuem sabonete líquido, papel e álcool em gel. Do lado de fora do banheiro possui um chuveiro, o qual deveria ser interno. Não existe nenhuma fiscalização no banheiro.

A falta de padronização e limpeza das barracas são uns dos problemas do Parque. As barracas não possuem água potável para higienização das mãos e dos produtos vendidos no local, não possui energia para ligar demais eletrodomésticos, tendo apenas um fio para a luz, impossibilitando de ligar freezer, microondas e ademais. Também não se encontra banheiros próximo ao espaço de alimentação, o que dificulta a higienização dos visitantes. Enfim, a situação em que se encontra o Parque Ipanema é preocupante. Precisa da atenção não somente do Poder Público para realizar a reestruturação do espaço, mas também da conscientização dos seus usuários (visitantes, moradores e comerciantes) de modo a manter o local preservado.

\section{RESULTADOS E DISCUSSÕES}

Foram iniciados dois tipos de questionários para facilitar a aplicabilidade deste método, buscando atingir o maior número possível de moradores e turistas. Utilizou-se o programa Google Formulários $^{2}$, que foi aberto no dia 14/08/2018 e fechado no dia 03/09/2018, atingindo 134 pessoas. A escolha quanto ao tempo/dias que esteve aberto foi apenas para a proposição de maior quantidade e proximidade aos dias que iriam ser aplicados os questionários presenciais. Justificase este processo pelo fato de que quando foi aplicado o presencial, muitos participantes informaram parentes, amigos e conhecidos que já haviam ido ao mesmo parque e que talvez gostariam de responder ao questionário e ainda não haviam recebido o link referente ao

\footnotetext{
${ }^{2}$ Google Formulários. Disponível em: https://goo.gl/forms/EOsnEg8o6vCKtPdc2. Aberto entre os dias: 14/08/2018 e 03/09/2018
} 
questionário online ${ }^{3}$. O questionário presencial foi aplicado nos dias 24, 25 e 26/08/2018, aproveitando datas que aconteceriam eventos no local para atingir um maior público para as respostas, obtendo total de 200 questionários respondidos.

O roteiro de perguntas, tanto para os moradores quanto para os visitantes, fundamentou-se quanto a estruturação dos equipamentos, segurança do local, alimentos vendidos no parque, iluminação e eventos, visto que foi um único modelo para os dois identificando-os no início do questionário. Foram aplicados em diferentes locais do Parque para diversificar o público. Ao final, foi conseguido um espaço amostral de 334 pessoas entrevistadas, sendo 134 online e 200 pessoas in loco, notando que $67 \%$ dos visitantes são mulheres e $33 \%$ são homens.

Os próprios moradores da cidade são os que mais frequentam o Parque Ipanema (93\%) em seu momento de lazer, mas também outros visitantes (7\%) das cidades de Coronel Fabriciano, Timóteo e Governador Valadares. Pode-se perceber que 37\% dos entrevistados possuíam de 13 a 23 anos, sendo este o maior público frequentador do parque; $24 \%$ possuíam de 24 a 34 anos; $17 \%$ entre 35 a 45 anos de idade e os outros $14 \%$ possuíram de 46 a 56.

A frequência dos entrevistados no parque resultou em $31 \%$ por motivo de eventos, $37 \%$ frequentam aos finais de semana, $14 \%$ nos dias de semana, $11 \%$ em feriados, $3 \%$ marcaram mais de uma alternativa, e, por isso, a questão foi anulada, e os outros $4 \%$ marcaram férias escolares. Os equipamentos mais utilizavam pelos visitantes são: $40 \%$ usam a pista para caminhada com mais frequência; $23 \%$ utilizam o galpão de eventos; $11 \%$ o lago, como foi observado ao aplicar a pesquisa os visitantes fazendo piquenique no entorno do mesmo; $12 \%$ frequentam a casa do Papai Noel montada todos os anos em dezembro; $8 \%$ frequentam a ilha elevada; e $6 \%$ frequentam o anfiteatro. A respeito do Parque da Ciência, 98\% das pessoas disseram estar a favor da reabertura deste, sendo de interesse da maior parte da população, pois eram beneficiados com novos conhecimentos no momento de lazer, de uma forma dinâmica.

A limpeza dos banheiros do Parque, variando entre 1 para RUIM e 5 para ÓTIMO, foi avaliado como: $50 \%$ das pessoas votaram 1; $31 \%$ votaram 2; e $19 \%$ votaram 3 . Os dados dessa pergunta são preocupantes visto que a maioria dos visitantes não estão satisfeitos com a limpeza

\footnotetext{
${ }^{3}$ Link do Formulário. Disponível em: https://goo.gl/forms/5thL0kh7YxuyLOJC2. Aberto entre os dias: 14/08/2018 e 03/09/2018
} 
do local, questionando a falta de papel higiênico, falta de portas e de limpeza adequada. Muitas pessoas não sabiam avaliar o anfiteatro do Parque, não sabendo do que se tratava por não haver placa indicativa: $33 \%$ das pessoas votaram entre 1 e 2 , pois não conheciam ou nunca viram espetáculo acontecendo no local; $47 \%$ avaliaram como 3; $13 \%$ nota 4 ; e apenas $7 \%$ notas 5 .

A respeito da praça de alimentação do Parque: 19\% das pessoas votaram 1 (RUIM) e 18\% das pessoas votaram 2; $37 \%$ votaram 3; $16 \%$ das pessoas pontuaram como 4; e $10 \%$ das pessoas votaram 5 (ÓTIMO). Os dados dessa pergunta são preocupantes, visto que a maioria dos visitantes não consideram as barracas um lugar ótimo para se alimentar, e no momento da entrevista in loco, muitos questionaram a padronização e a limpeza das barracas.

A segurança dos brinquedos (Playground), foi avaliada em: $18 \%$ das pessoas votaram 1 (RUIM) e 14\% das pessoas votaram 2; $30 \%$ votaram 3 e $27 \%$ das pessoas votaram 4; restando apenas $11 \%$ que votaram 5 (ÓTIMO). O playground do parque foi o que obteve a melhor nota entre todos os equipamentos, mas não significa que o mesmo não precisa ser reestruturado. Com relação a estrutura do Campo de Futebol (gramado, gol e grades), as notas obtidas foram: 39\% das pessoas responderam nota 3 , outros $20 \%$ responderam nota 2 , apenas $15 \%$ avaliaram como 1 e $17 \%$ disseram ser nota 4 . Os outros $9 \%$ avaliaram como ÓTIMO (nota 5).

Um dos resultados preocupantes observa-se na avaliação sobre o quanto se sentem seguros no Parque, variando entre 1 para INSEGURO e 5 para TOTALMENTE SEGURO: $34 \%$ das pessoas votaram 1; $25 \%$ votaram 2, outras $25 \%$ das pessoas votaram 3; $9 \%$ votaram 4; e apenas $7 \%$ das pessoas votaram 5. O policiamento no parque foi questionado: $79 \%$ responderam não ser suficiente para segurança dos todos e $21 \%$ responderam que sim. Os dados afirmam ser imprescindível o reforço da segurança no parque para o bem-estar de todos. A iluminação noturna também precisa ser observada, visto que $67 \%$ dos visitantes informaram não ser suficiente, e apenas $31 \%$ votaram que SIM. E $2 \%$ dos entrevistados não votaram.

Os entrevistados apresentaram algumas sugestões para a melhoria do Parque, e as mais citadas: reforçar a segurança alegando ser insuficiente o número de policiais; construção de um posto policial dentro do parque municipal para que os visitantes se sintam mais seguros; padronização das barracas da praça de alimentação, com água encanada e esgoto; aumento de postes de iluminação e troca de lâmpadas queimadas; e higienização diária dos banheiros. 
Ao entrevistar os comerciantes, notou-se insegurança e muitos deles não quiseram responder às perguntas do questionário, totalizando um espaço amostral de 14 questionários respondidos de um total de 49 barracas. Ao questionar uma comerciante o porquê de tanta insegurança para responder os questionários, informou haver um plano de reestruturação do parque, mas pelo modo como foi apresentado a eles causou rejeição. Contou que a prefeitura pediu que saíssem, dando um prazo para que retirassem suas barracas. A comerciante está a 13 anos no Parque Ipanema, e acredita que a proposta de reestruturação é boa, porém gostaria de ser indenizada ou de uma segurança de que terá o direito de usufruir da barraca estruturada.

O jornal G1 (30/11/2017) ${ }^{4}$ com a notícia "Grupo busca acordo para manter barracas no Parque Ipanema, em Ipatinga" retratou que os comerciantes do parque entraram em processo judicial para que não retirasse as barracas do local dentro do prazo determinado pela prefeitura até que o juiz possa ouvir o poder público, e, ouvir o município para depois fazer o pedido liminar. Pediram aos comerciantes que desocupassem as barracas até novembro de 2017, mas estenderam para dezembro de 2017. O Ministério Público recomendou ao governo municipal a retomada dos espaços públicos ocupados de forma irregular do município em especial do Parque Ipanema. Segundo a reportagem, pelos critérios orientados pelo Ministério Público, e, segundo a lei aprovada em setembro sobre o exercício de atividade no parque, os vendedores exercem o trabalho de forma irregular, sem licença de funcionamento atuando em área de preservação permanente além de ocuparem irregularmente o solo em patrimônio tombado.

Com os dados, notou-se que $29 \%$ dos comerciantes possuem barracas a 13 anos, e os demais variando entre 2 a 16 anos. A média do salário dos comerciantes resulta em: 79\% possuem uma renda de 1 a 2 salários mínimos, $14 \%$ possui 3 ou mais e os outros $7 \%$ não quiseram responder. A maioria (93\%) afirma que gostaria de uma infraestrutura padronizada, informando que a prefeitura fornece energia apenas para a iluminação da barraca e não para congeladores e demais eletrodomésticos, além de não possuir água para facilitar a higienização, fazendo com que muitos tenham que buscar no banheiro do parque que fica a alguns metros de distância das barracas. Mas notou-se que $7 \%$ se encontra satisfeito com sua infraestrutura.

\footnotetext{
4 Notícia: "Grupo busca acordo para manter barracas no Parque Ipanema, em Ipatinga" disponível em: http://g1.globo.com/mg/vales-mg/mgintertv-2edicao/videos/t/edicoes/v/grupo-busca-acordo-para-manter-barracasno-parque-ipanema-em-ipatinga/6326116/ Acesso em: 21 jul. 2018
} 
A segurança no parque avaliada pelos comerciantes, resultou em: $50 \%$ se sentem seguros e os outros $50 \%$ não, um resultado curioso visto que ao entrevistá-los, muitos informaram o fato de ter apenas um policial de motocicleta rodando pelo parque, número insuficiente devido ao tamanho do local. Houve divergência quanto ao questionamento sobre o pagamento de alguma taxa para instalação das barracas no parque, notando-se que não é devidamente regulamentado. A maioria (60\%) disse não pagar nenhuma taxa e 30\% dos entrevistados afirmaram pagar mensalmente. São diversos os produtos/alimentos vendidos nas barracas do parque, mesmo com a dificuldade em relação a água, energia e infraestrutura. Dentre eles: banana e batata frita, refrigerante, cerveja, água de coco e água mineral. Algumas, com variações de almoço, lanches, salgados, chips, hambúrguer, pão com linguiça, pão com pernil, pastel e outros produtos.

A entrevista com o Poder Público foi representada pela Sec. Municipal de Turismo do município, Aparecida Pires Sampaio, que aceitou responder as perguntas na condição de "turismóloga". Aparecida contou que o Parque Ipanema foi construído em 1980 pelo paisagista Burle Marx, com objetivo inicial de preservar o ribeirão Ipanema, mas passou por diversas alterações na sua estruturação, com a inclusão de quadras poliesportivas, inserção de linha férrea em um dos seus limites e introdução de espécies da flora que não são nativas da Mata Atlântica. O período de maior visitação é durante as férias (dezembro e janeiro).

Quanto a estruturação e segurança do local, se é de responsabilidade exclusiva da Prefeitura Municipal ou se conta com a cooperação de parceiros, a entrevistada não soube informar. Não tem conhecimento de realização de alguma pesquisa de demanda com os visitantes, mas disse que pela iniciativa da Secretaria de Desenvolvimento Econômico e Turismo ainda não ocorreu. Informou que no Parque Ipanema não é permitido a circulação dos ambulantes, e que as barracas existentes não têm autorização para estarem instaladas no local.

O potencial do parque é observado pela entrevistada como: "o principal ícone do município, é o espaço mais democrático da cidade que recebe o morador e o visitante. Espaço de espetáculos, shows, atividades física e lazer”. Para ela, as fraquezas \limitações do local estão na não existência de uma praça de alimentação, o que poderia aumentar o fluxo de visitantes; e por não haver um calendário fixo de eventos. Informou que há legislação e normas que contribuem para a proteção do parque, pois o espaço foi tombado pelo serviço de patrimônio e está inserido 
na Área de Proteção Ambiental (APA) Ipanema. Contou que não há concessão do espaço para os comerciantes, e que não é cobrado nenhuma taxa. A entrevistada não soube responder se existe fiscalização sanitária dos vendedores no local, controle de quantas pessoas visitam o Parque Ipanema e como são programados os eventos.

\section{PROPOSTA DE REESTRUTURAÇÃO PARA O PARQUE IPANEMA.}

Tendo em vista os resultados dos questionários analisados, a respeito da infraestrutura turística do local, foi percebido a insegurança tanto dos visitantes quanto dos comerciantes que se instalaram no mesmo. Objetivando direcionar mais segurança para os turistas, é sugerido nos questionários através das respostas abertas um número maior de policiais rodando no Parque e para maior segurança a instalação de um posto policial nas dependências do Parque urbano. Um investimento em iluminação nas áreas menos movimentadas do local é primordial para que se sintam seguros. Com relação a praça de alimentação é sugerido a padronização de tais, com fiscalização sanitária e diversidade no cardápio, questionando nas respostas que só possuem "Banana e batata" frita para a comercialização.

É importante ressaltar que a privatização do banheiro, cobrando um valor simbólico para a contribuição da limpeza do mesmo, seria importante para evitar que sofra ato de vandalismo e para colaborar que continue limpo com os elementos mínimos disponíveis para o uso como papel higiênico, sabonete líquido, álcool em gel, e papel toalha. Placas de sinalização turística precisam ser melhoradas e implementadas no local, visto que se você não conhece o parque ou visita-o pela primeira vez, não consegue explorar todas as áreas do local por não possuir placas com boas condições para indicar os locais, principalmente de entrada do Parque, que deveria obter um tamanho maior e mais chamativo para evitar que um turista passe direto e deixe de conhecer o cartão postal da cidade.

O parque Ipanema possui uma boa infraestrutura, mas precisa ser reestruturado e atualizado visto que se degradou com o passar dos anos, sofreu vandalismo, e principalmente a segurança no

quesito iluminação que não é o suficiente para a demanda do espaço. É importante frisar o aumento do policiamento no local, como foco principal para essa reestruturação. Alguns eventos são realizados no parque, mas, todavia, tem a necessidade de serem mais divulgados. Desta forma, 
consegue atingir o maior público e tem o maior reconhecimento do cartão postal da cidade, proporcionando segurança para os visitantes e principalmente para os moradores que deixam de visitar o local por medo em período noturno.

\section{CONCLUSÃO}

Em virtude dos dados de toda a metodologia aplicada e respondendo ao questionamento inicial do trabalho, foi constatado que o parque necessita de uma reestruturação de forma consciente, tanto do Poder Público, quanto da população e dos comerciantes. É notório que o parque possui diversas potencialidades, o local se encontra com a infraestrutura mínima, sendo água, banheiros e equipamentos de lazer, mas não exerce um de seus objetivos iniciais que é proteger a margem do ribeirão Ipanema.

Entretanto, foi identificado que possui grande fragilidade no quesito segurança e estrutura da praça de alimentação. Muitos questionaram a falta de policiamento no parque e no entorno dele principalmente em período noturno, o que precisa ser analisado urgentemente. Acrescentando ao questionamento de que não possui exatamente uma praça de alimentação com vigilância sanitária, foi constatado que a praça é uma área de invasão, motivo pelo qual não recebe infraestrutura pela prefeitura, como água para higienização, esgoto encanado e energia, e não possui cuidados com a área de preservação ambiental e principalmente sem condições de funcionamento referente a limpeza e vigilância sanitária.

Quando se trata do Parque da Ciências, a maior parte da população sente falta de tal equipamento, que era tido como fonte de conhecimento de uma forma dinâmica e gratuita para a sociedade. Uma sugestão, a ser acrescida no trabalho, é o cercamento na área de Playground para evitar que crianças saiam do olhar dos pais e se percam no Parque. O controle de ambulantes dentro do parque evitando a poluição visual e o lixo acumulado onde se encontram. Fazer um controle de entrada no Parque seria essencial para que haja um cuidado especial do local, valor que poderia ser simbólico destinado ao controle da limpeza dos banheiros.

\section{REFERÊNCIAS BIBLIOGRÁFICAS}

BRAZ AQUINO, Cássio Adriano; DE OLIVEIRA MARTINS, José Clerton. Ócio, lazer e tempo livre na sociedade do consumo e do trabalho. Revista mal-estar e subjetividade, v. 7, n. 2, 2007. 
ISSN 1994-0098

DUMAZEDIER, Joffre. Lazer e cultura popular. São Paulo: Perspectiva, 1973.

IBGE disponível em: <https://cidades.ibge.gov.br/brasil/mg/ipatinga/panorama>. Acesso em: 09 jun. 2018.

LIMA, M.L.C. (Eco)turismo em unidades de Conservação. In: RODRIGUES, A.B. (org.). Ecoturismo no Brasil: possibilidades e limites. São Paulo: Contexto, 2003.

MACEDO, S. S. Parques Urbanos no Brasil = Brazilian Urban Parks / Silvio Soares Macedo e Francine Gramacho Sakata - 2.ed.- São Paulo: Editora da Universidade de São Paulo: Imprensa Oficial da Universidade de São Paulo, 2003 - [Coleção Quapá]. In SILVA, Janaína Barbosa; PASQUALETTO, Antônio. O Caminho dos Parques Urbanos Brasileiros: da origem ao século XXI. Estudos, v. 40, n. 3, p. 287-298, 2013.

MACEDO, Silvio Soares. Quadro do Paisagismo no Brasil. São Paulo: Gráfica Pancrom, 1999. In SILVA, Janaína Barbosa; PASQUALETTO, Antônio. O Caminho dos Parques Urbanos Brasileiros: da origem ao século XXI. Estudos, v. 40, n. 3, p. 287-298, 2013.

MORAES, José Augusto. Coletânea "IPATINGA - Cidade Jardim". Disponível em: http://euamoipatinga.com.br/pracas/noticias.asp?codigo=6 Acesso em: 02 set. 2018. PREFEITURA MUNICIPAL DE IPATINGA. Parque Ipanema patrimônio de Ipatinga que precisa ser preservado. Disponível em: <http://www.ipatinga.mg.gov.br/>. Acesso em: 08 jun. 2018.

SILVA, Janaína Barbosa; PASQUALETTO, Antônio. O Caminho dos Parques Urbanos Brasileiros: da origem ao século XXI. Estudos, v. 40, n. 3, p. 287-298, 2013. 